
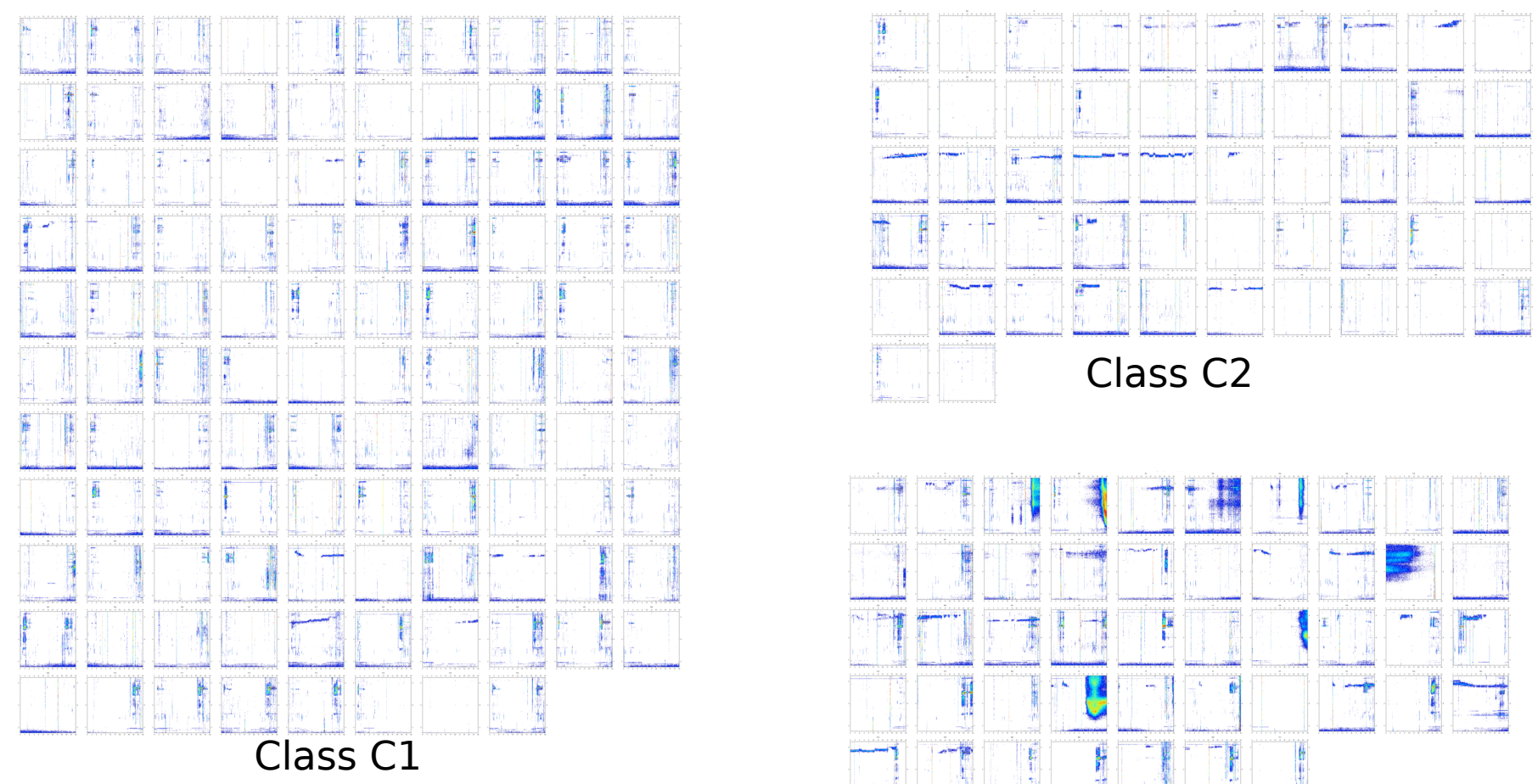

\title{
Class C2
}
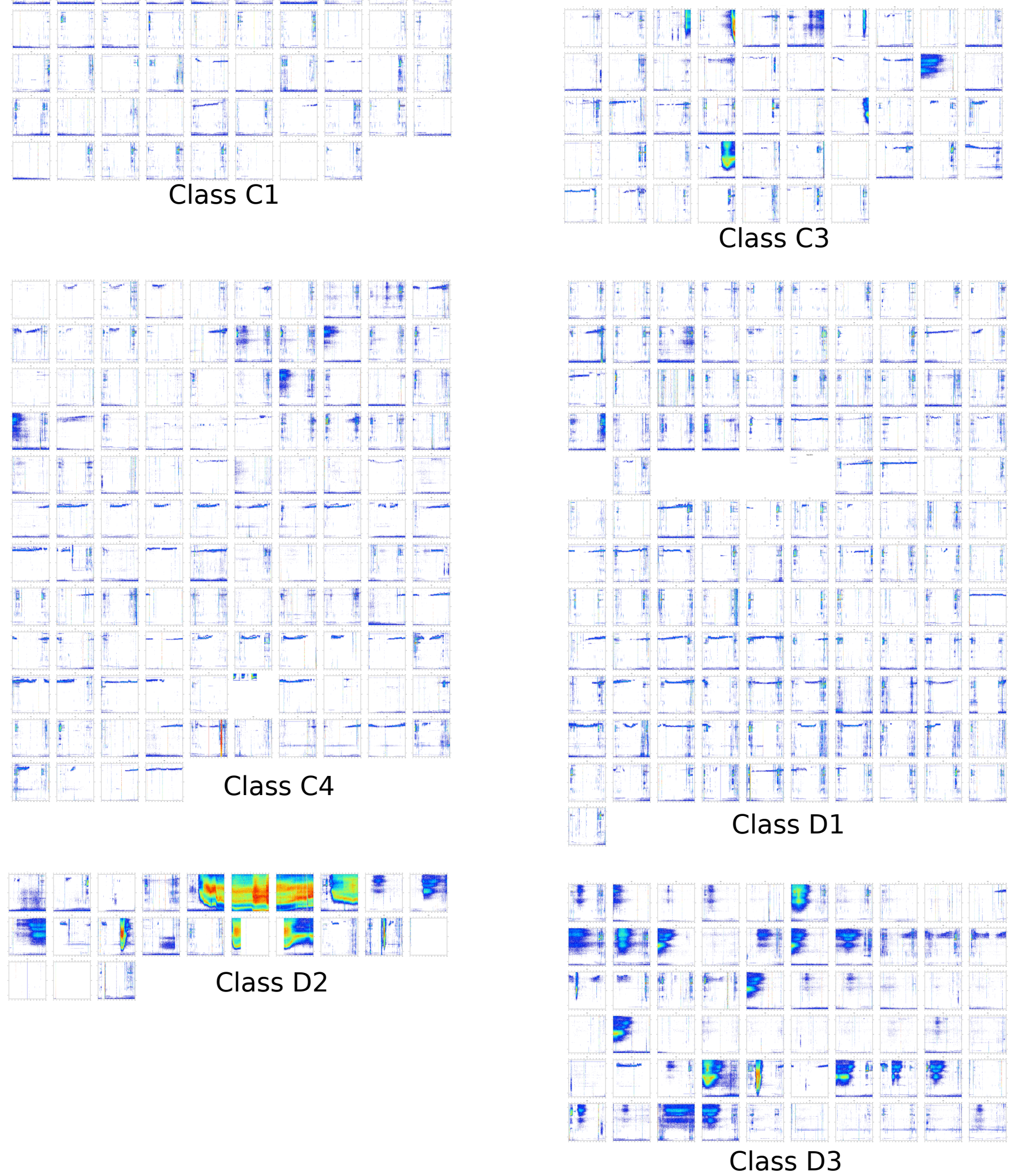

Supplemental Figure S7: Daily spectrograms for classes C and D, not showing evidences of snowmelt activity. 